\title{
Grid Integration of PV Through Three Switches Leg Dual-Input Single-Output DC-DC-AC Converter
}

\author{
Mahdi Azizi and Sima Aznavi
}

\begin{abstract}
This paper presents a novel application of a three switches leg based Dual-Input Single-Output Converter in grid integration of a low power Photovoltaic (PV) system. In this application, an input of the dc-dc-ac converter is connected to the PV while the other is connected to a battery. The ac output is connected to the grid and delivers PV's generated power. The operation principle of Dual-Input Single-output converter and its control scheme for this application are discussed. To verify the performance of the proposed configuration in grid integration of $\mathrm{PV}$ panel, two main operating scenarios are simulated. The results validate the effective performance of the proposed configuration in tracking the desired output power of converter.
\end{abstract}

Index Terms - Multi Input Converter (MIC), Hybrid PVBattery Power Generation, Space Vector Switching, Power Management.

\section{INTRODUCTION}

In recent years many endeavors have been devoted to reduce the pollutant energy generation by increasing the utilization of renewable energy sources. Renewable energy generation is usually associated with uncertainty, which induces power mismatches between power demand and supply. In literature, efforts have been made to reduce the power mismatches by optimal siting of renewable energy generations [1]. However, dependency of renewable energy resources such as solar generation to weather condition, increases the tendency for combining various types of energy sources to provide a reliable, high quality and efficient energy generation [2], [3]. Thus, during the last years, energy legislators have concentrated on improvement of energy efficiency, and several studies have emphasized on the importance of eco-efficiency, and sustainability [4].

Energy storage systems have extensively been recommended as an effective option for mitigating the fluctuations associated with renewable energy sources. This has motivated the researchers to concentrate on optimal strategies for development of hybrid systems including energy storage and with renewable energies in smart systems such as microgrids and communities [5]. To facilitate the combination of renewable energies with energy storage technologies, Multi-input Converters (MIC) have developed significantly within the past few years [6], [7]. MICs reduce the cost of the system by using less components while at the same time can deliver the power of several sources with different levels of power and voltage to a common load [8], [9], [10]. In reference [11], a new family of multi-input converters based on three switches leg is introduced. The analysis of the proposed Dual-Input Single-Output converter

Mahdi Azizi is with Tehran Regional Electrical Company, Tehran, Iran (email: ma-azizi@trec.co.ir).

Sima Aznavi is $\mathrm{PhD}$ student of Electrical Engineering at University of Nevada-Reno, Reno, NV, U.S (e-mail: s.aznavi@nevada.unr.edu). has shown that the proposed topology reduces the number of devices and corresponding driving circuit by $25 \%$, in comparison with its conventional counterparts while at the same time has the least effect on energy conversion efficiency. The inputs of this topology are interchangeable, so that they can be used for different types of renewable energy sources. Moreover, it can provide bidirectional power flow which is necessary in presence of energy storage systems such as batteries.

In this paper, a novel application for the proposed topology in [11] for grid integration of a small PV-battery system is presented. This hybrid structure is widely used in smart building systems [5], [12]. The individual inputs of the proposed topology are connected to the PV and battery storage system. The Boost-Boost and Buck-Boost operation modes make the converter flexible in mitigating the uncertainties associated with solar power generation. The surplus of solar energy is used to charge the battery in BuckBoost mode, while the power mismatch due to unpredicted reduction in solar power generation is compensated by the battery through Boost-Boost mode. The AC output is connected to the grid and delivers solar generation through proper control method of the inverter.

\section{CONFIGURATION OF THE GRID CONNECTED MIC}

As shown in Fig. 1, the first input of the converter is connected to the battery storage and the other input is connected to the dc terminal of the PV. In this paper, the lower terminals of the legs are assumed to be dc voltage terminals. However due to symmetry, the upper terminals can also be used for this purpose. The battery terminal operates in buck mode during the charging, while boost mode of operation is utilized during discharging. The other terminal, however, always operates as a boost converter. Therefore, the converter has two operation modes of boost-boost and buckboost. $S_{3}$ and $S_{6}$ alongside with $D_{1} D_{2}$ and $D_{4} D_{5}$ are used to boost the voltage, while $S_{1} S_{2}$ and $S_{4} S_{5}$ pairs with $D_{3}$ and $D_{6}$ are used in buck mode. The switching pattern for all operation

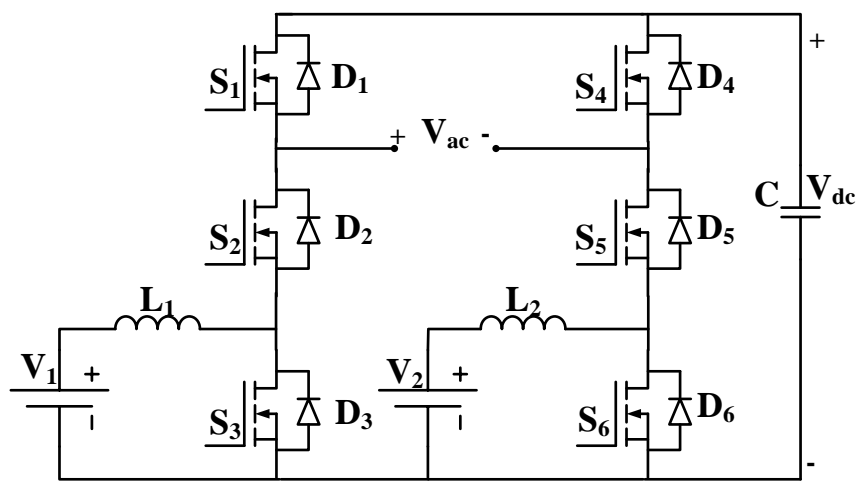

Fig. 1 : Synopsis of Dual-Input Single-Output dc-dc-ac converter 
modes, are described in the following sections.

\section{A. Boost-Boost Operation}

Similar to a conventional boost converter, boost operation of this converter has two sub-intervals. While $S_{3}$ and $S_{6}$ are switched on, the inductors are charged by $V_{1}$ and $V_{2}$ and the inverter is able to apply any desired voltage at the output terminal as a full bridge inverter. It should be considered that the inductor current passes through $S_{3} / S_{6}$, while the state of the other switches is determined by the required output voltage vector. The $S_{3} / S_{6}$ lasts are $O N$ during $d_{1} T_{S}$ and $d_{2} T_{S}$ respectively, where $d_{1}$ and $d_{2}$ are duty cycles of $S_{3}$ and $S_{6}$ and $\mathrm{T}_{\mathrm{S}}$ is switching period.

In the second subinterval, turning off $\mathrm{S}_{3} / \mathrm{S}_{6}$ causes the inductor currents to flow through $\mathrm{D}_{1} \mathrm{D}_{2} / \mathrm{D}_{4} \mathrm{D}_{5}$ the dc bus capacitor. In this time interval the zero voltage vector is applied to the inverter and zero output voltage is applied to ac load. The time intervals of this operating mode are $\left(1-d_{1}\right) T_{S}$ and $\left(1-d_{2}\right) T_{S}$ for $S_{3}$ and $S_{6}$, respectively. Normally, two dc input voltages are not the same. Therefore, two other modes are defined: 1) $S_{3}$ is on and $S_{6}$ is off. 2) $S_{6}$ is on and $S_{3}$ is off. The simplest way to control the output ac voltage in these operation modes is applying the zero vectors to the inverter. Here, it is assumed that $\mathrm{S}_{3} / \mathrm{S}_{6}$ are turned on simultaneously and turned off according to the duty cycle.

According to above discussion, inverter applies nonzero voltage vector only when both switches S3 and S6 are turned on. Therefore, maximum modulation index of the inverter is identified as follows,

$$
M_{\text {max }}=\min \left(d_{1}, d_{2}\right)
$$

If the leg operates in discontinuous conduction mode (DCM), then the inductor current is equal to zero after (1$\left.\mathrm{d}_{1} / 2\right) \mathrm{T}_{\mathrm{S}}$. Two upper switches must be turned on and the inverter applies zero voltage to the load. In fact, in this case converter is behaves similar to the second state. This situation does not impose new limitation on the inverter.

\section{B. Buck-Boost Operation}

The connected leg to the energy storage element (e.g. battery) operates in buck mode while it is being charged. Here, $V_{1}$ in Fig. 1 is assumed to be the terminal voltage of a battery pack. Buck operation mode can also be divided into two subintervals. During the first interval, in which the current is flowing into the battery, $S_{1}$ and $S_{2}$ are conducting. Under this condition, the inverter's ability in applying all possible voltage vectors is limited. In the second interval, $\mathrm{S}_{3}$ is $\mathrm{ON}$, and $\mathrm{S}_{1}$ and $\mathrm{S}_{2}$ are switched on/off according to the required output voltage. In this sub interval there is no limitation on the inverter to apply the control switching vectors.

The other switching leg is always operating as a boost converter. In order to optimize the inverter operating mode, the buck and boost operations of the converter should be synchronized. While $\mathrm{S}_{6}$ is conducting during the interval of $\mathrm{d}_{2} \mathrm{~T}_{\mathrm{s}}, \mathrm{S}_{3}$ should be ON for a time interval of $\left.\left(1-\mathrm{d}_{1}\right) \mathrm{T}_{\mathrm{s}}\right)$, and when $S_{1}$, and $S_{2}$ are switched $O N, S_{3}$ and $S_{4}$ are turned $O N$ state and zero vector is applied to the load.

In practice, duty cycles of switches are not necessarily the same, due to different values of $\mathrm{V}_{1}$ and $\mathrm{V}_{2}$. Therefore, two other modes are defined according to the state of $S_{3}$ and $S_{6}$. The simplest way to control the output ac voltage in these operation modes is to apply the zero state to the inverter switches. Therefore, the available time interval for applying nonzero vector in a switching period is the minimum value of $\mathrm{d}_{2} \mathrm{~T}_{\mathrm{s}}$ and $\left(1-\mathrm{d}_{1}\right) \mathrm{T}_{\mathrm{s}}$ and the maximum modulation index is

$$
M_{\text {max }}=\min \left\{1-d_{1}, d_{2}\right\}
$$

In buck mode and DCM, at the end of the second interval, when the converter current reaches to zero, $S_{3}$ must be turned off. The inverter applies zero voltage vectors to the load in this state. The middle switch of the leg should be switched off from the beginning of this state to the end of the switching period and only upper switch remains on to apply zero voltage across the load. It is obvious that the DCM operation mode increases the limitations on the inverter modulation index.

\section{Inverter Mode of Operation}

Inverter's switching states must be determined according to the buck and boost mode, and the load required voltage vector. As shown in Tables. I and II, when lower switches are turned on, the proper voltage vector is applied to the load. If one of the lower switches is turned off, then the zero voltage vector is applied by the inverter. Voltage vector in each switching interval is selected according to the inverter's control system command and the lower switches states, which are determined by their control signals applied by converter control system.

TABLE. I: Inverter Voltage Polarity According to the State of the Lower Switches

\begin{tabular}{cccc}
\hline States & $\mathrm{S}_{3}$ & $\mathrm{~S}_{6}$ & Inverter Output voltage \\
\hline $1-2-3-4$ & ON & ON & $+\mathrm{V}_{\mathrm{dc}} /-\mathrm{V}_{\mathrm{dc}} / 0$ \\
$8-9$ & ON & OFF & $-\mathrm{V}_{\mathrm{dc}} / 0$ \\
$6-7$ & OFF & ON & $+\mathrm{V}_{\mathrm{dc}} / 0$ \\
5 & OFF & OFF & 0 \\
\hline
\end{tabular}

\begin{tabular}{|c|c|c|c|c|c|c|c|c|c|c|c|}
\hline \multirow{2}{*}{ State } & \multirow{2}{*}{$\mathrm{S}_{1}$} & \multirow{2}{*}{$\mathrm{S}_{2}$} & \multirow{2}{*}{$\mathrm{S}_{3}$} & \multirow{2}{*}{$\mathrm{S}_{4}$} & \multirow{2}{*}{$\mathrm{S}_{5}$} & \multirow{2}{*}{$\mathrm{S}_{6}$} & \multirow{2}{*}{$\begin{array}{l}\text { Inverter } \\
\text { Voltage }\end{array}$} & \multicolumn{2}{|c|}{ Leg1 } & \multicolumn{2}{|c|}{ Leg2 } \\
\hline & & & & & & & & Buck & Boost & Buck & Boost \\
\hline 1 & OFF & $\mathrm{ON}$ & $\mathrm{ON}$ & OFF & $\mathrm{ON}$ & $\mathrm{ON}$ & 0 & $(1-d) T_{S}$ & $\mathrm{dT}_{\mathrm{S}}$ & $(1-d) T_{S}$ & $\mathrm{dT}_{\mathrm{S}}$ \\
\hline 2 & $\mathrm{ON}$ & OFF & ON & $\mathrm{ON}$ & OFF & $\mathrm{ON}$ & 0 & $(1-d) T_{S}$ & $\mathrm{dT}_{\mathrm{S}}$ & $(1-d) T_{S}$ & $\mathrm{dT}_{\mathrm{S}}$ \\
\hline 3 & ON & OFF & ON & OFF & $\mathrm{ON}$ & $\mathrm{ON}$ & $+\mathrm{V}_{\mathrm{dc}}$ & $(1-d) T_{S}$ & $\mathrm{dT}_{\mathrm{S}}$ & $(1-d) T_{S}$ & $\mathrm{dT}_{\mathrm{S}}$ \\
\hline 4 & OFF & $\mathrm{ON}$ & $\mathrm{ON}$ & $\mathrm{ON}$ & OFF & $\mathrm{ON}$ & $-\mathrm{V}_{\mathrm{dc}}$ & $(1-d) T_{S}$ & $\mathrm{dT}_{\mathrm{S}}$ & $(1-d) T_{S}$ & $\mathrm{dT}_{\mathrm{S}}$ \\
\hline 5 & $\mathrm{ON}$ & $\mathrm{ON}$ & OFF & $\mathrm{ON}$ & $\mathrm{ON}$ & OFF & 0 & $\mathrm{dT}_{\mathrm{S}}$ & $(1-d) T_{S}$ & $\mathrm{dT}_{\mathrm{S}}$ & $(1-d) T_{S}$ \\
\hline 6 & $\mathrm{ON}$ & $\mathrm{ON}$ & OFF & $\mathrm{ON}$ & OFF & $\mathrm{ON}$ & 0 & $\mathrm{dT}_{\mathrm{S}}$ & $(1-d) T_{S}$ & $(1-d) T_{S}$ & $\mathrm{dT}_{\mathrm{S}}$ \\
\hline 7 & $\mathrm{ON}$ & $\mathrm{ON}$ & OFF & OFF & $\mathrm{ON}$ & $\mathrm{ON}$ & $+\mathrm{V}_{\mathrm{dc}}$ & $\mathrm{dT}_{\mathrm{S}}$ & $(1-d) T_{S}$ & $(1-d) T_{S}$ & $\mathrm{dT}_{\mathrm{S}}$ \\
\hline 8 & $\mathrm{ON}$ & OFF & $\mathrm{ON}$ & $\mathrm{ON}$ & $\mathrm{ON}$ & OFF & 0 & $(1-d) T_{S}$ & $\mathrm{dT}_{\mathrm{S}}$ & $\mathrm{dT}_{\mathrm{S}}$ & $(1-d) T_{S}$ \\
\hline 9 & OFF & $\mathrm{ON}$ & $\mathrm{ON}$ & $\mathrm{ON}$ & $\mathrm{ON}$ & OFF & $-V_{d c}$ & $(1-d) T_{S}$ & $\mathrm{dT}_{\mathrm{S}}$ & $\mathrm{dT}_{\mathrm{S}}$ & $(1-d) T_{S}$ \\
\hline
\end{tabular}

TABLE. II: Inverter Switching States Considering dc/dc Converter Operation 
Inverter switching of the proposed converter could be implemented either by space vector or by carrier based modulation method, similar to the conventional inverters. But, these approaches must be modified by considering the buck and boost operations of the converter. For this purpose, the load required voltage vector and its duration are calculated. When lower switches of the legs are turned on, the proper voltage vector is applied to the load. Time durations of the active and zero vectors are calculated using

$T_{\text {active }}=\frac{V_{m}}{V_{D C}} T_{S} \sin (\omega t+\varphi)$

$T_{\text {zero }}=T_{S}-T_{\text {active }}$

If one of the lower switches is turned off, then the zero voltage vector is applied to the load. Maximum available time for applying the active vector to the load is given in

$\left\{\begin{array}{lr}T_{\text {active }} \leq \min \left(d_{1} T_{S}, d_{2} T_{S}\right) & \text { Boost }- \text { Boost } \\ T_{\text {active }} \leq \min \left(d_{1} T_{S},\left(1-d_{2}\right) T_{S}\right) & \text { Boost }- \text { Buck }\end{array}\right.$

Voltage vector in each switching interval is selected according to the inverter control system command and the lower switches statuses, which are determined by their control signals, as will be explained in the next section.

\section{CONVERTER CONTROL APPROACH}

The control system of the converter consists of three main blocks. The maximum power is captured from the PV and is delivered to the dc bus by the MPPT control block. If this power is more than the output power, the dc bus voltage regulation control block maintains the voltage at the proper level. The third block controls the active and reactive power injected to the grid through inverter's modulation index. The outputs of these control blocks are duty cycle of dc-dc terminal switches.

\section{A. DC Bus Voltage Controller}

This control block consists of two control loop. The inner loop is a current control loop and the outer loop is a voltage control loop. Similar to the conventional two stage converters, the proposed dual-input topology suffers from low frequency current ripple. The source of ripple is the second harmonic fluctuations in DC bus voltage and can be omitted easily using a large size capacitor [13], [14].

In this paper, to decrease low frequency current ripple, the outer control loop is modified by adding a notch filter. Equation (5) shows the transfer function of filter and it's bode diagram is shown in Fig. 2. As can be seen, this filter has unity gain except in second harmonic frequency. Second harmonic error of dc bus voltage is attenuated by the notch filter. Therefore, double frequency dc bus voltage fluctuations do not appear in battery current. Filtered dc bus voltage error passes through the PID controller.

$$
C_{\text {Filter }}=\frac{S^{2}+1.50796 S+568489.21}{S^{2}+75.398+568489.21}
$$

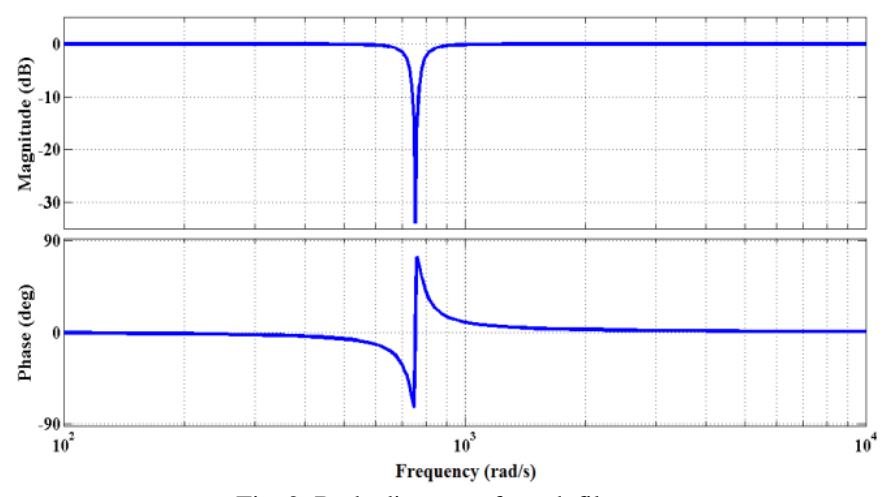

Fig. 2. Bode diagram of notch filter

\section{B. Inverter Output Active and Reactive Power Control}

The third block controls the converter output voltage in stand-alone mode of operation. It is also responsible to control the active and reactive power injected to the grid in the grid connected mode. The applied method is based on the single-phase p-q theory [15], as shown in Fig. 3.

In this method, first by using (6), imaginary components of the inverter voltage and current which lag the real signal by $90^{\circ}$ are created to be used as the $\mathrm{q}$ component in the stationary frame.

$$
\left\{\begin{array}{l}
s_{R}=s_{F} \sin (\phi) \\
s_{\text {Im }}=s_{F} \sin \left(\phi-\frac{\pi}{2}\right)
\end{array}\right.
$$

where, $S_{R}$ and $S_{I m}$ are real and imaginary current or voltage signals, respectively. Using these two signals and by considering (7), the variables will be transformed to the synchronous reference frame. Where $\theta$ is the grid voltage angle.

$$
\left[\begin{array}{l}
s_{d} \\
s_{q}
\end{array}\right]=\left[\begin{array}{cc}
\sin \theta & -\cos \theta \\
\cos \theta & \sin \theta
\end{array}\right]\left[\begin{array}{l}
s_{S R} \\
s_{S \mathrm{Im}}
\end{array}\right]
$$

With d-q components of the signals, the control algorithm can be implemented similar to three-phase d-q control system.

\section{Simulation Results}

To demonstrate the effectiveness of the proposed configuration, two operating scenarios are taken into account. The simulation results for the first and second scenarios are shown in Figs. 4-12. Simulation parameters are given in Table. III.

TABLE III: SIMULATION PARAMETERS

\begin{tabular}{cccc}
\hline dc bus Voltage & $220 \mathrm{~V}$ & Output Filter & $3 \mathrm{mH}, 68 \mu \mathrm{F}$ \\
\hline Battery Voltage & $40 \mathrm{~V}$ & Input Inductor & $2 \mathrm{mH}$ \\
\hline Switching Frequency & $30 \mathrm{kHz}$ & dc Bus Capacitor & $2 \mathrm{mF}$ \\
\hline Grid Impedance & $1 \Omega, 3 \mathrm{mH}$ & Grid Voltage & $110 \mathrm{~V} / 60 \mathrm{~Hz}$ \\
\hline
\end{tabular}



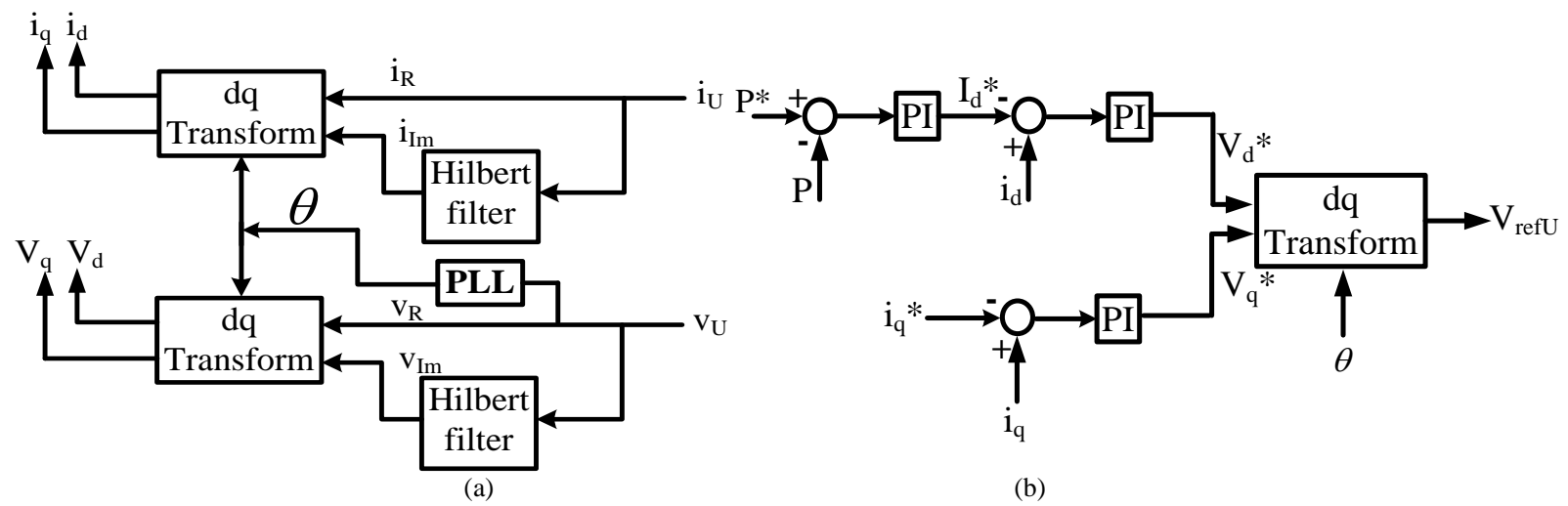

(b)

Fig. 3. Inverter control block: a) voltage and current transformation to dq axis, b) active and reactive power control

In the first scenario, the converter's power injection to the grid $(600 \mathrm{~W})$, is less than the maximum power of the PV. Thus, the DC bus voltage control block absorbs the extra power to charge the battery. At $\mathrm{t}=0.6 \mathrm{~s}$, the command of power injection increases to $1200 \mathrm{~W}$, which is more than the maximum power of the PV. The DC bus voltage control block compensates this power shortage by discharging the battery. The results of first scenario show that the inverter control blocks successfully control the output power and the dc bus voltage at the required level by charging/discharging the battery.
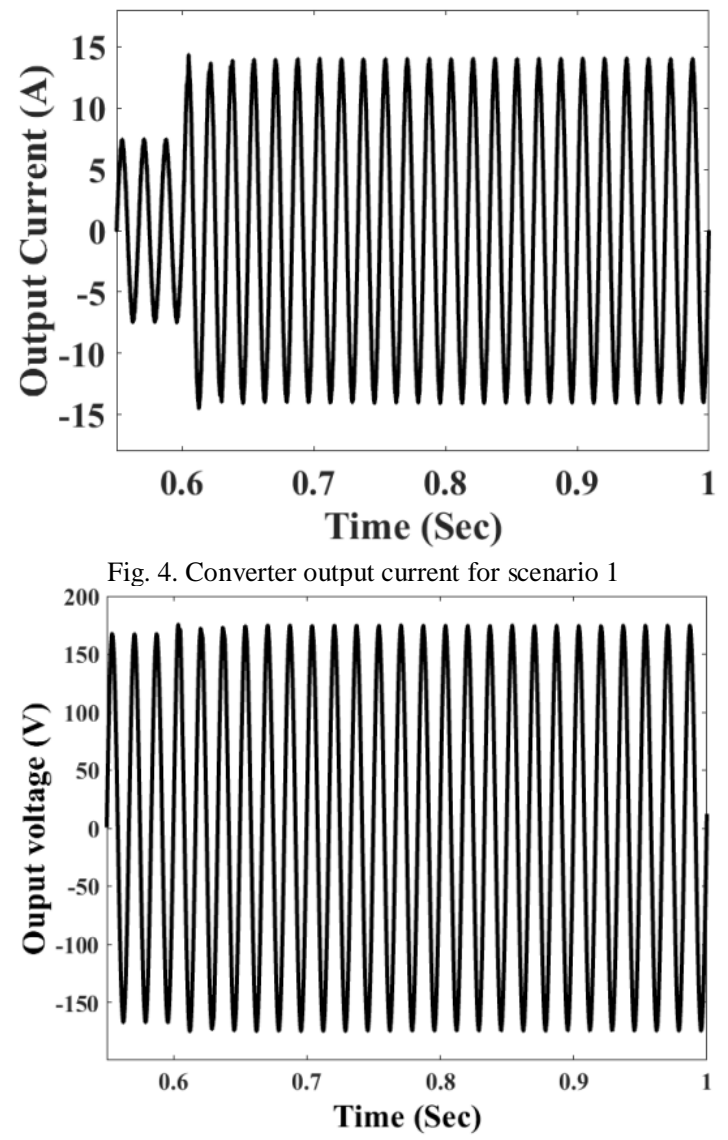

Fig. 5. Converter output voltage for scenario 1

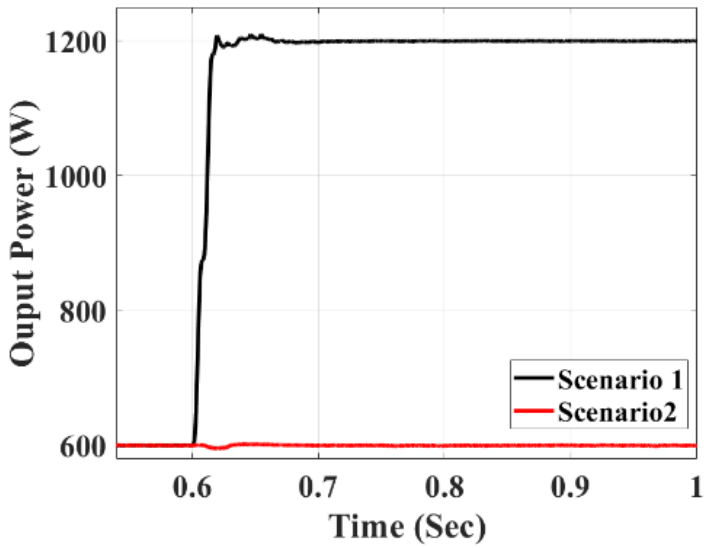

Fig. 6. Injected power to grid for scenario1 vs. scenario2

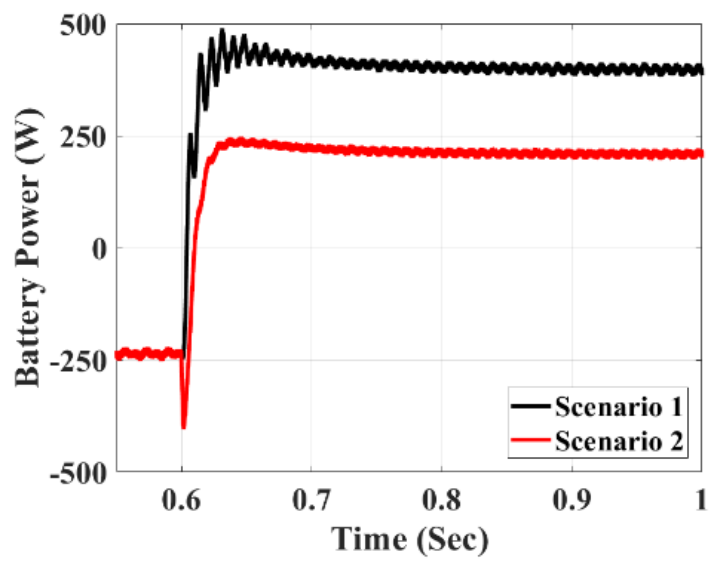

Fig. 7. Battery power for scenario1 vs. scenario 2

As can be seen in Fig. 8, DC bus voltage is properly regulated by its controller. As illustrated, after the injected power command increases, the bus voltage begins to decrease, because the input power is lower than the output power. But, the DC bus voltage controller immediately discharges battery to maintain power balance. The small drop of dc bus voltage testifies proper response speed of its control loop. As can be seen in Fig. 9, with the proposed filter, the battery current has negligible second harmonic ripple, and the transient behavior of battery current such as overshoot and settling time is acceptable. 


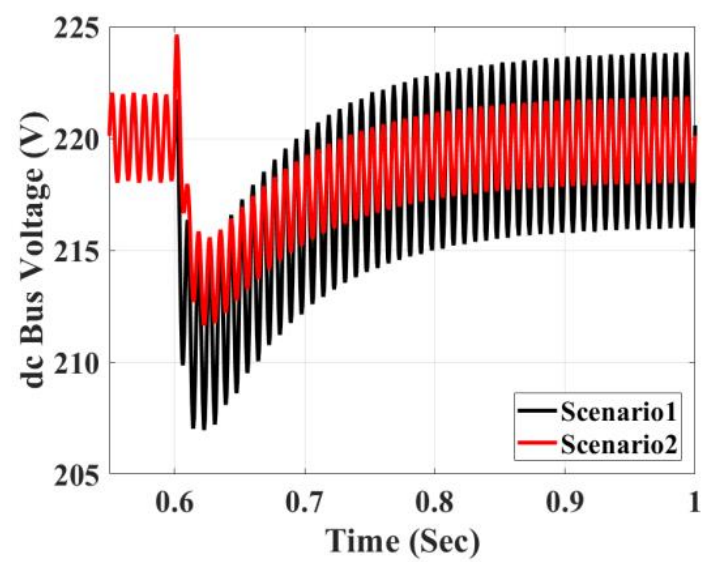

Fig. 8 dc bus voltage for scenario1 vs. scenario 2

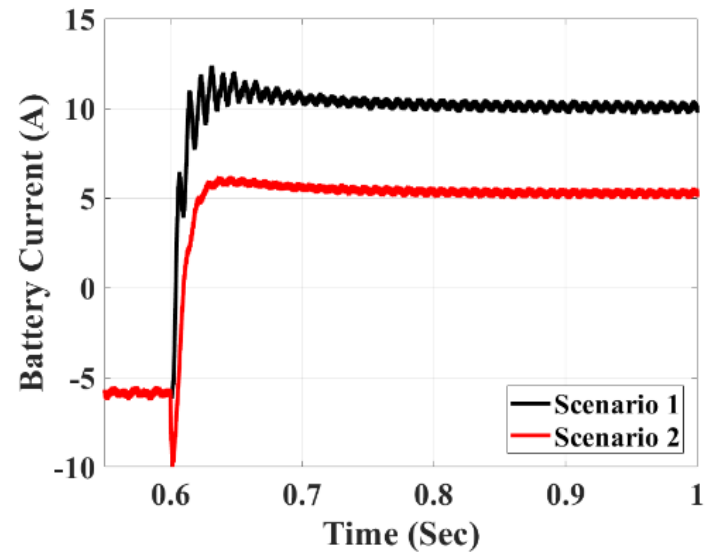

Fig. 9. Battery current for scenario1 vs. scenario 2

In the second scenario, the initial conditions are similar to the first case. at $t=0.6 \mathrm{~s}$ with a reduction in solar radiation, the output power of PV decreases as shown in Fig. 10. To prevent the reduction of the bus voltage, and control the output power of converter at $600 \mathrm{~W}$, the dc bus control block discharges the battery to deliver its power to the bus. The results show the battery current direction is changed to keep the dc bus voltage at a required level and maintain the converter's power balance as shown in Figs. 8-9. Although the two-way power flow may require a more intelligent protection system in a smart power grid [16], it is necessary in presence of energy storage systems such as batteries. Since the command of power injection is constant, the output voltage, current do not change, as illustrated in Figs. 11-12.

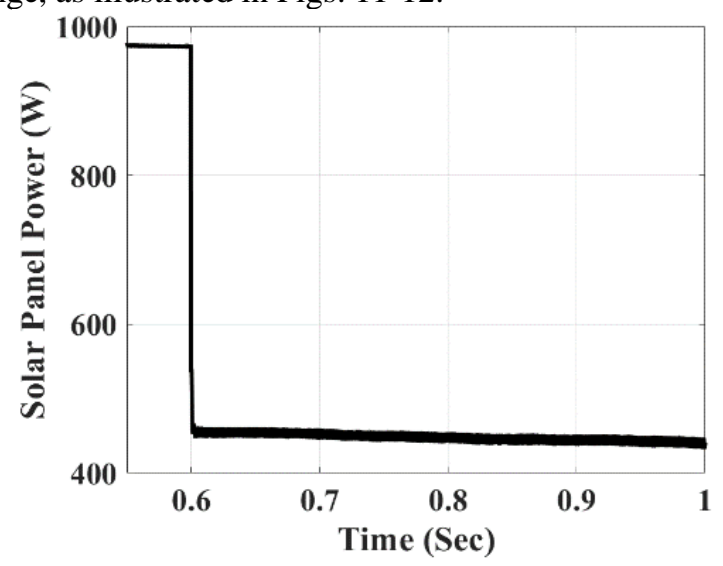

Fig. 10. PV generated power scenario 2

\section{CONCLUSIONS}

In this paper, an application for the Dual-Input SingleOutput converter in grid integration of a small PV-battery system is presented. The operation principle and control scheme for this application are discussed and the performance of the converter in controlling the output power is verified through two operating scenarios. The results verified the given theoretical analysis and its performance. In these scenarios, the excess energy from the PV is absorbed to charge the battery, while the power shortage is compensated by discharging the battery.

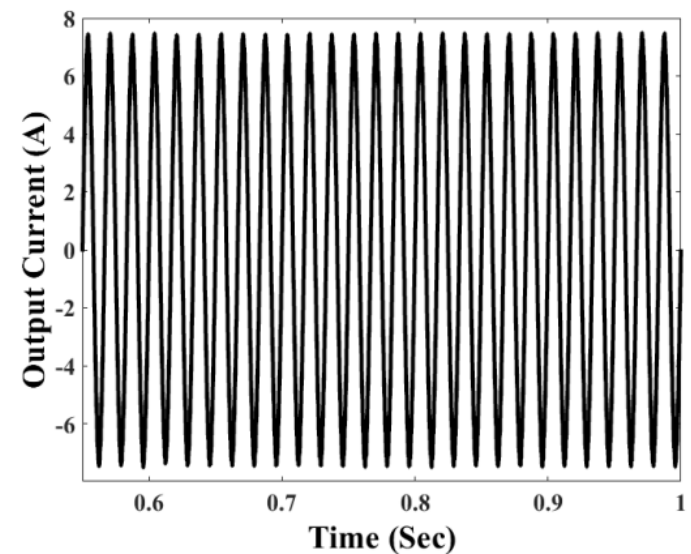

Fig. 11. Converter output current for scenario 2

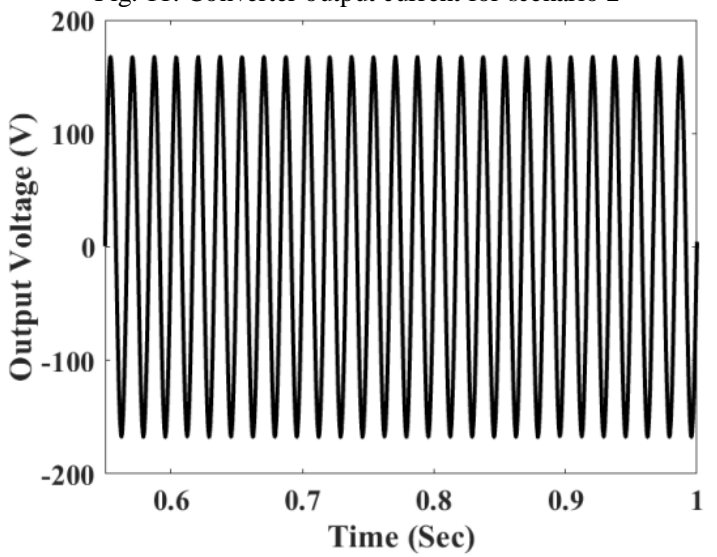

Fig. 12. Converter output voltage for scenario 2

\section{REFERENCES}

[1] A. Forooghi Nematollahi, A. Dadkhah, O. Asgari Gashteroodkhani, and B. Vahidi, "Optimal sizing and siting of DGs for loss reduction using an iterative-analytical method," Journal of Renewable and Sustainable Energy, vol. 8, no. 5, p. 055301, 2016.

[2] R. Faraji and H. Farzanehfard, "Soft-Switched Nonisolated High Step-Up Three-Port DC-DC Converter for Hybrid Energy Systems," in IEEE Transactions on Power Electronics, vol. 33, no. $12,2018$.

[3] M. Jabbari and M. S. Dorcheh, "Resonant Multi-input/Multioutput/Bidirectional ZCS Step-Down DC--DC Converter With Systematic Synthesis for Point-to-Point Power Routing," in IEEE Transactions on Power Electronics, vol. 33, no. 7, pp. 6024-6032, 2018.

[4] M. Mirmozaffari, , "Eco-Efficiency Evaluation in Two-Stage Network Structure: Case Study: Cement Companies", Iranian Journal of Optimization (IJO). Volume 11, Issue 2, Dec. 16, 2018.

[5] S. Aznavi, P. Fajri and M. Rasheduzzaman, "Hierarchical Energy Management Strategy for a Community of Multi Smart Homes," in IECON 2018 - 44th Annual Conference of the IEEE Industrial Electronics Society, Washington, DC, USA, 2018, pp. 176-181.

[6] A. Fatemi, M. Azizi, M. Mohamadian, A. Yazdian Varjani and M. Shahparasti, "Single-Phase Dual-Output Inverters With Three-Switch Legs," in IEEE Transactions on Industrial Electronics, vol. 60, no. 5, pp. 1769-1779, May 2013.

[7] Z. Saadatizadeh, P. C. Heris, E. Babaei, and M. Sabahi, "A New Nonisolated Single-Input Three-Output High Voltage Gain 
Converter with Low Voltage Stresses on Switches and Diodes," IEEE Trans. Ind. Electron., 2019.

[8] Y. Li, X. Ruan, D. Yang, F. Liu and C. K. Tse, "Synthesis of Multiple-Input DC/DC Converters," in IEEE Transactions on Power Electronics, vol. 25, no. 9, pp. 2372-2385, 2010.

[9] N. K. Reddi, M. R. Ramteke, H. M. Suryawanshi, K. Kothapalli and S. P. Gawande, "An Isolated Multi-Input ZCS DC-DC FrontEnd-Converter Based Multilevel Inverter for the Integration of Renewable Energy Sources," in IEEE Transactions on Industry Applications, vol. 54, no. 1, pp. 494-504, 2018.

[10] B. L. H. Nguyen, H. Cha, and H. G. Kim, "Single-Phase SixSwitch Dual-Output Inverter Using Dual-Buck Structure," IEEE Trans. Power Electron., 2018.

[11] M. Azizi, M. Mohamadian and R. Beiranvand, "A New Family of Multi-Input Converters Based on Three Switches Leg," in IEEE Transactions on Industrial Electronics, vol. 63, no. 11, pp. 6812-6822, 2016

[12] S. Aznavi, P. Fajri and A. Asrari, "Smart Home Energy Management Considering Real-Time Energy Pricing of Plug-in Electric Vehicles," in 2018 IEEE Energy Conversion Congress and Exposition (ECCE), Portland, OR, USA, 2018, pp. 67-72.

[13] Abrishamifar, A., Ale Ahmad, A., Mohamadian, M.: 'Fixed switching frequency sliding mode control for single phase unipolar inverters', IEEE Trans. Power Electron, 2012, 27, (5), pp. 2570-2574.

[14] A.Ale Ahmad, A. Abrishamifar, S. Samadi, "Low-frequency current ripple reduction in front-end boost converter with singlephase inverter load", IET Power Electron, Vol. 5, Iss. 9, pp. 1676 - 1683., 2012.

[15] Haque, M.T.: "Single-phase PQ theory", IEEE 33rd Annual Power Electronics Specialists Conference PESC ,vol.4, pp.18151820, 2002.

[16] O. A. Gashteroodkhani, B. Vahidi, and A. Zaboli, "Time-time matrix z-score vector-based fault analysis method for seriescompensated transmission lines," Turkish Journal of Electrical Engineering \& Computer Sciences, vol. 25, pp. 2647-2659, 2017. 